\title{
Contact tracing of in-flight measles exposures: lessons from an outbreak investigation and case series, Australia, 2010
}

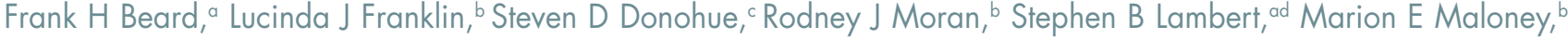 \\ Jan L Humphreys, ${ }^{\mathrm{C}}$ Jessica Rotty, ${ }^{\mathrm{b}}$ Nicolee V Martin, ${ }^{\mathrm{e}}$ Michael J Lyon, ${ }^{\mathrm{f}}$ Thomas Tran $^{9}$ and Christine E Selveya \\ Correspondence to Frank H Beard (e-mail: Frank_Beard@health.qld.gov.au).
}

Objective. To describe a 2010 outbreak of nine cases of measles in Australia possibly linked to an index case who travelled on an international flight from South Africa while infectious.

Methods. Three Australian state health departments, Victoria, Queensland and New South Wales, were responsible for the investigation and management of this outbreak, following Australian public health guidelines.

Results. An outbreak of measles occurred in Australia after an infectious case arrived on a 12-hour flight from South Africa. Only one of four cases in the first generation exposed to the index case en route was sitting within the two rows recommended for contact tracing in Australian and other guidelines. The remaining four cases in subsequent generations, including two health care workers, were acquired in health care settings. Seven cases were young adults. Delays in diagnosis and notification hampered disease control and contact tracing efforts.

Conclusion. Review of current contact tracing guidelines following in-flight exposure to an infectious measles case is required. Alternative strategies could include expanding routine contact tracing beyond the two rows on either side of the case's row or expansion on a case-by-case basis depending on cabin layout and case and contact movements in flight. Releasing information about the incident by press release or providing generic information to everyone on the flight using e-mail or text messaging information obtained from the relevant airline, may also be worthy of consideration. Disease importation, inadequately vaccinated young adults and health care-related transmission remain challenges for measles control in an elimination era.

$\mathrm{M}$ easles has been eliminated from Australia ${ }^{1}$ due to high rates of immunity, now predominantly vaccine-derived, in the population, with most cases since 1999 either imported or linked to an imported case. ${ }^{2}$ Most imported measles cases arrive in Australia by air, usually on long international flights, with some cases infectious during flight. In-flight transmission can lead to community-based outbreaks with susceptible contacts at risk of serious complications from measles.

While any passenger or crew member could be exposed before, during or after a flight (before arrival at airport or during check-in, boarding, disembarkation, baggage collection and other related processes), ${ }^{3}$ considerable public health resources would be required for individual follow-up of all passengers on a flight.
Australian guidelines take a risk-based approach in recommending contact tracing of passengers in the same row and two rows on either side of a laboratory-confirmed case who is infectious during a flight of any duration. The Australian guidelines justify limiting contact tracing by citing questionable public health value of follow-up given the high levels of population immunity; few published reports of in-flight transmission; and air handling mechanisms, including high-efficiency particulate air filters and limited Iongitudinal air circulation, which minimize transmission risk. $^{4}$

European guidelines recommend that contact tracing for exposure to confirmed measles cases should be considered if the flight occurred within the previous five days but may also be considered outside five days

\footnotetext{
Communicable Diseases Branch, Queensland Health, Brisbane, Queensland, Australia.

Communicable Disease Prevention and Control Unit, Department of Health, Melbourne, Victoria, Australia.

Townsville Public Health Unit, Queensland Health, Townsville, Queensland, Australia.

Queensland Paediatric Infectious Diseases Laboratory, Queensland Medical Children's Research Institute and Sir Albert Sakzewski Virus Research Centre, Brisbane, Queensland, Australia.

Surveillance Branch, Office of Health Protection, Australian Government Department of Health and Ageing, Canberra, Australia.

Public Health Virology Laboratory, Forensic and Scientific Services, Queensland Health, Brisbane, Queensland, Australia.

Victorian Infectious Diseases Reference Laboratory, Melbourne, Victoria, Australia.

Submission date: 27 June 2011 ; Publication date: 25 August 2011

doi: 10.5365/wpsar.2011.2.2.010
} 
by countries where measles elimination is achieved or within reach to limit further spread. ${ }^{5}$ They recommend that all passengers and crew be considered for contact tracing, commencing with children below two years of age and passengers seated in the same row as the index case, proceeding outwards row by row for as long as it is possible to carry out post-exposure prophylaxis or containment measures. ${ }^{5}$

The US Centers for Disease Control and Prevention (CDC) protocol recommends contact tracing of passengers in the same row and two rows on either side of a laboratory-confirmed case, along with any 'babes in arms' and flight crew from the same cabin (personal communication: K Marienau, CDC, 22 April 2011).

In-flight transmission of measles has been reported but it has generally been accepted, based on published reports $^{3,6-8}$ and reviews, ${ }^{9,10}$ that the risk to other passengers and crew is low. The effectiveness of contact tracing for exposure to measles on aircraft has been questioned. ${ }^{11}$

In this paper we describe a 2010 outbreak of measles in Australia possibly linked to an index case who travelled on an international flight from South Africa while infectious.

\section{METHODS}

\section{Case definition}

Measles is a nationally notifiable disease in Australia. The case definition for notification requires laboratory definitive evidence of measles (either virus isolation, nucleic acid or antigen detection or serological evidence of recent infection in the absence of recent vaccination); or a combination of clinical and epidemiological evidence. $^{12}$

\section{Outbreak investigation and response}

In the elimination era, measles cases and clusters are treated as an urgent public health priority in Australia. Detailed national guidelines are available for public health management of measles, including the use of vaccine and normal human immunoglobulin prophylaxis. ${ }^{4,13}$

Three Australian state health departments, Victoria, Queensland and New South Wales, were responsible for the investigation and management of the 2010 outbreak, including interviewing cases and contacts and providing advice about prophylaxis where appropriate. The Australian health department obtained flight manifests for the international flight from the relevant airline and incoming international passenger details from the Australian immigration department and distributed these to state health departments. The Communicable Diseases Network of Australia (CDNA) ${ }^{14}$ provided advice on contact tracing.

\section{Laboratory analyses}

Enzyme-linked immunosorbent serological assay testing of serum specimens for measles IgM and IgG were undertaken by local diagnostic laboratories.

Polymerase chain reaction (PCR) testing and genotyping were conducted by Queensland Health Forensic and Scientific Services (QHFSS) and Victorian Infectious Diseases Reference Laboratory (VIDRL). Genotyping involves the amplification of part of the $\mathrm{N}$ (nucleocapsid) gene, and genotype classification is based on nucleic acid sequencing of the PCR products. ${ }^{15}$

\section{RESULTS}

The index case (case 1) in this outbreak was an 11-year-old refugee from Malawi (Figure 1), a region experiencing a known measles epidemic. ${ }^{16}$ She had onset of prodromal symptoms on 1 August 2010 and flew from Malawi to South Africa on 2 August 2010 then on to Australia the same day (Table 1). She arrived in Australia on 3 August 2010. She was hospitalized in Victoria the following day due to otitis media and poor oral intake. Formal notification to the Victorian Department of Health was delayed. While initial laboratory results showed a positive measles IgM, treating physicians considered this to be due to documented measles vaccination in a refugee camp in Malawi five days before departure (Table 2). A throat swab was forwarded to VIDRL who notified the Victorian Department of Health on 6 August of a positive PCR result, but at this time the case, still without a visible rash, was assumed to be vaccine related. However, on 16 August 2010, VIDRL notified the Victorian Department of Health that genotyping confirmed the infection to be due to genotype B3 wild-type measles virus.

Case 2, a 25-year-old Australian resident who had been on the same international flight as the index case, was notified to the Victorian Department of Health 
Figure 1. Chain of transmission by date of onset, measles outbreak, July to September 2010, cases numbered in order of notification



Table 1. Summary details of individual linked measles cases, July to September 2010, cases numbered in order of notification

\begin{tabular}{|c|c|c|c|c|c|c|c|}
\hline $\begin{array}{c}\text { Case } \\
\text { no. }\end{array}$ & $\begin{array}{c}\text { Age } \\
\text { (years) }\end{array}$ & Sex & $\begin{array}{l}\text { Onset date } \\
\quad(2010)\end{array}$ & $\begin{array}{c}\text { Epidemiological link } \\
\text { Hospitalization status } \\
\text { Method of diagnosis and virus genotype }\end{array}$ & $\begin{array}{c}\text { Row \& } \\
\text { seat no. }\end{array}$ & $\begin{array}{l}\text { Vaccination } \\
\text { status }\end{array}$ & Resident of \\
\hline $\begin{array}{c}1 \\
\text { (index } \\
\text { case) }\end{array}$ & 11 & $\mathrm{~F}$ & 1 August & $\begin{array}{l}\text { Index case, flight from South Africa on } 2 \text { August } \\
\text { Hospitalized - otitis media and poor oral intake } \\
\text { PCR, genotype B3 }\end{array}$ & $47 \mathrm{E}$ & $\begin{array}{l}1 \text { dose } 5 \text { days } \\
\text { before flight to } \\
\text { Australia }\end{array}$ & - \\
\hline 2 & 25 & M & 10 August & $\begin{array}{l}\text { Same flight as index case } \\
\text { Hospitalized - confluent rash and deranged } \\
\text { liver function tests } \\
\text { PCR, genotype B3 }\end{array}$ & $51 \mathrm{E}$ & $\begin{array}{l}0 \text { documented } \\
\text { doses }\end{array}$ & Australia \\
\hline 3 & 36 & M & 15 August & $\begin{array}{l}\text { Same flight as index case } \\
\text { Not hospitalized } \\
\text { PCR, genotype B3 }\end{array}$ & $48 \mathrm{H}$ & $\begin{array}{l}0 \text { documented } \\
\text { doses }\end{array}$ & Australia \\
\hline 4 & 29 & M & 13 August & $\begin{array}{l}\text { Same flight as index case } \\
\text { Hospitalized } \\
\text { PCR, genotype B3 }\end{array}$ & $64 \mathrm{~J}$ & $\begin{array}{l}0 \text { documented } \\
\text { doses }\end{array}$ & United Kingdom \\
\hline 5 & 32 & $\mathrm{~F}$ & 27 August & $\begin{array}{l}\text { Hospital staff member, provided care } \\
\quad \text { to case } 6 \\
\text { Not hospitalized } \\
\text { PCR, genotype B3 }\end{array}$ & - & $\begin{array}{l}0 \text { documented } \\
\text { doses }\end{array}$ & Australia \\
\hline 6 & 38 & $\mathrm{~F}$ & 10 August & $\begin{array}{l}\text { Same flight as index case, link not initially } \\
\text { recognized } \\
\text { Hospitalized - confluent rash and urticaria } \\
\text { PCR, genotype B3 }\end{array}$ & $50 \mathrm{D}$ & $\begin{array}{l}0 \text { documented } \\
\text { doses }\end{array}$ & Australia \\
\hline 7 & 42 & $\mathrm{~F}$ & 2 September & $\begin{array}{l}\text { Hospital staff member, in hospital emergency } \\
\text { department at same time as case } 6 \\
\text { Hospitalized - pneumonitis } \\
\text { PCR, genotype B3 }\end{array}$ & - & $\begin{array}{l}0 \text { documented } \\
\text { doses }\end{array}$ & Australia \\
\hline 8 & 34 & $\mathrm{~F}$ & 17 September & $\begin{array}{l}\text { At hospital emergency department same time } \\
\quad \text { as case } 7 \\
\text { Not hospitalized } \\
\text { Serological diagnosis only }\end{array}$ & - & $\begin{array}{l}0 \text { documented } \\
\text { doses }\end{array}$ & Australia \\
\hline 9 & 62 & M & 17 September & $\begin{array}{l}\text { At general practice clinic same time as case } 7 \\
\text { Not hospitalized } \\
\text { Serological diagnosis only }\end{array}$ & - & $\begin{array}{l}0 \text { documented } \\
\text { doses }\end{array}$ & Australia \\
\hline
\end{tabular}


Table 2. Timeline of measles importation, possible in-flight transmission and community outbreak, Australia, August to September 2010, cases numbered in order of notification

\begin{tabular}{|c|c|}
\hline Date & Event \\
\hline 28 July 2010 & Documented MMR vaccination of index case (case 1), refugee camp, Malawi \\
\hline 1 August 2010 & Onset of symptoms case 1 \\
\hline 2 August 2010 & $\begin{array}{l}\text { Case } 1 \text { flies from Malawi to South Africa. } \\
\text { Case } 1 \text { departs South Africa on flight to Australia. }\end{array}$ \\
\hline 3 August 2010 & Flight arrives Australia \\
\hline 4 August 2010 & Case 1 hospitalized \\
\hline 6 August 2010 & $\begin{array}{l}\text { VIDRL* notifies PCR positive measles result (case } 1 \text { ) to Victorian Department of Health, assumed to be } \\
\text { vaccine related }\end{array}$ \\
\hline 16 August 2010 & VIDRL* notifies confirmation of genotype B3 wild-type virus (case 1) to Victorian Department of Health \\
\hline 17 August 2010 & $\begin{array}{l}\text { Case } 2 \text { notified to Victorian Department of Health: on same flight four rows from index case } \\
\text { Contact tracing, including the flight according to local guidelines, }{ }^{4} \text { commenced }\end{array}$ \\
\hline 19 August 2010 & $\begin{array}{l}\text { Case } 3 \text { notified to Queensland Department of Health: } 36 \text {-year-old on same flight as index case, one row } \\
\text { from index case }\end{array}$ \\
\hline 20 August 2010 & $\begin{array}{l}\text { Case } 4 \text { notified to Queensland Department of Health: } 29 \text {-year-old United Kingdom resident on same flight as } \\
\text { index case, initially thought to be seated one row from index case (later confirmed to be } 16 \text { rows away) } \\
\text { Emergency out-of-session Communicable Diseases Network of Australia teleconference convened to advise } \\
\text { on incident management recommends contact tracing be extended to passengers a further two rows } \\
\text { either side of the rows previously traced }\end{array}$ \\
\hline 3 September 2010 & $\begin{array}{l}\text { Case } 5 \text { notified to Queensland Department of Health: } 32 \text {-year-old staff member of Queensland hospital, no } \\
\text { history of overseas travel, no immediately apparent epidemiological link to outbreak; link subsequently } \\
\text { made to case } 6 \\
\text { Case } 6 \text { notified to Queensland Department of Health, on same flight as index case, three rows from index } \\
\text { case, not picked up in contact tracing, hospitalized in Queensland hospital, delayed diagnosis, source of } \\
\text { infection for case } 5\end{array}$ \\
\hline 8 September 2010 & $\begin{array}{l}\text { Case } 7 \text { notified to Queensland Department of Health: } 42 \text {-year-old staff member at the same Queensland } \\
\text { hospital as case } 6 \text {, exposed to case } 5 \text { in emergency department }\end{array}$ \\
\hline 20 September 2010 & $\begin{array}{l}\text { Case } 8 \text { notified to Queensland Department of Health: 34-year-old exposed to case } 7 \text { in emergency } \\
\text { department while infectious }\end{array}$ \\
\hline 22 September 2010 & $\begin{array}{l}\text { Case } 9 \text { notified to Queensland Department of Health: } 62 \text {-year-old exposed to case } 7 \text { in general practice } \\
\text { medical clinic while infectious }\end{array}$ \\
\hline
\end{tabular}

* Victorian Infectious Diseases Reference Laboratory

with PCR-confirmed measles on 17 August 2010. He had developed symptoms on 10 August 2010 and was hospitalized with a confluent rash and deranged liver function tests (Table 1). It was considered possible that acquisition could have occurred during the flight. Contact tracing following Australian guidelines, using flight manifests and information from the immigration department, was commenced. ${ }^{4,13}$ The index case's row, two rows behind, and a single row in front (due to adjacent toilets) were traced. Case 2 was seated four rows from case 1 (Table 1, Figure 2 ).

Case 3, a 36-year-old Australian resident who had been on the same international flight as the index case, seated in an adjacent row (Table 1, Figure 2), was identified through contact tracing by the Queensland Department of Health. He had developed symptoms on 15 August 2010 and was confirmed by PCR as having measles on 19 August 2010. While infectious he attended two general practice medical clinics and participated in a training workshop, prompting a large contact tracing exercise involving domestic flights, patients and staff from the general practice clinics and approximately 150 attendees of the workshop. No case of measles was identified in this case's contacts.

Case 4, a 29-year-old United Kingdom resident who had been on the same international flight as the index case, was notified to the Queensland Department of Health with PCR-confirmed measles on 20 August 2010. He had developed symptoms on 13 August 2010 and was hospitalized predominantly due to lack of suitable accommodation for him to care for himself. This case prompted another large contact tracing exercise by the Queensland and New South Wales state health departments. No case of measles was identified in this case's contacts. Case 4 was initially thought to have been seated within one row of the index case, but subsequently was found to have been seated 16 rows away. Numerals in his seat number had 
Figure 2. Seating plan for international flight showing confirmed measles cases

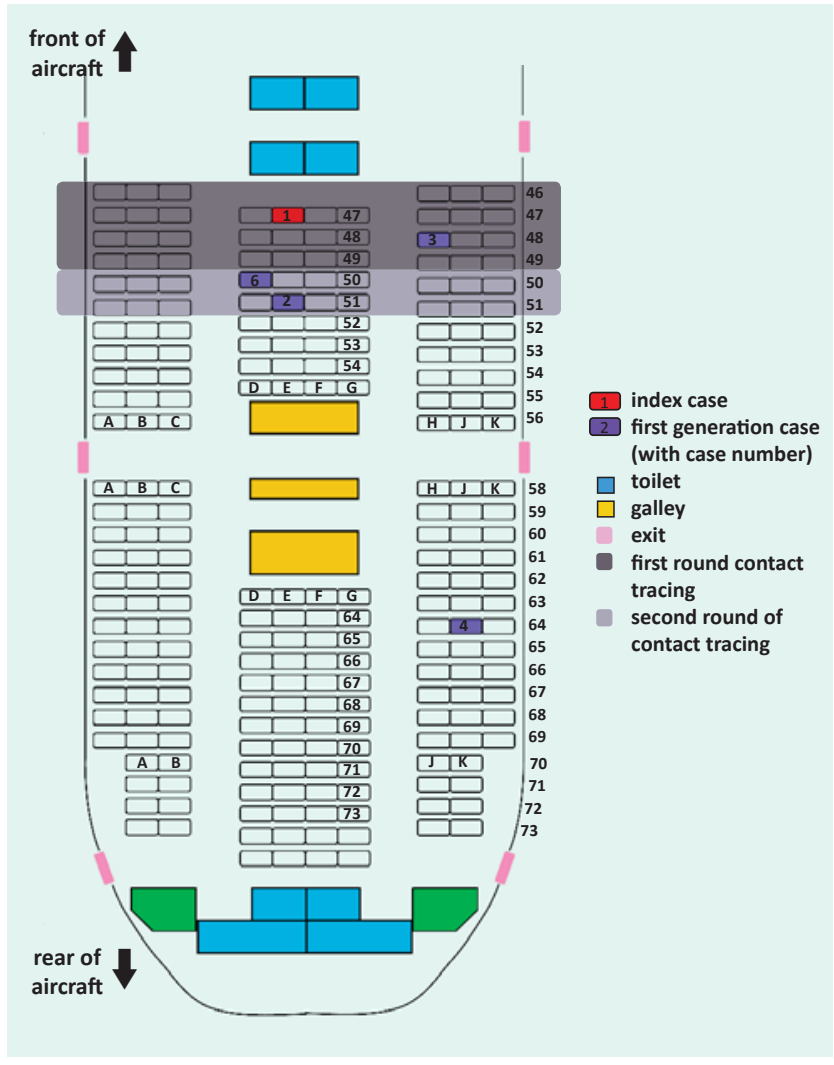

been transposed in communications - row 46 not 64 . This second case of possible in-flight transmission beyond the two row limit prompted an emergency out-of-session CDNA teleconference on 20 August 2010 where it was recommended that contact tracing be extended for a further two rows beyond those already traced.

Case 5, a 32-year-old health care worker from a Queensland hospital with no history of recent overseas travel, was notified to the Queensland Department of Health with PCR-confirmed measles on 3 September 2010. She had developed symptoms on 27 August 2010. While infectious she had visited the hospital emergency department (ED) as a patient and attended work (elsewhere in the hospital) on two days. Contact tracing of exposed staff, patients and visitors was commenced, along with a hospital measles vaccination campaign in which approximately 500 staff were vaccinated.

Further investigation identified that case 5 had contracted measles from a patient (case 6) she had been exposed to in the hospital. Case 6 was a 38-year-old who had been on the same international flight as the index case, seated three rows away. She was not identified in the second round of contact tracing for the flight, as her details were not included in the passenger information provided to the Queensland Department of Health. She developed symptoms on 10 August 2010 but her diagnosis was delayed as she had a confluent rash not recognized as measles for over a week until identification of typical measles illness in case 5.

Through follow-up it was identified that three of the four first generation cases (cases 2, 3 and 6) attended the BMX World Championships held in Pietermaritzburg, South Africa (27 July to 1 August): one competitor, one organizer and one family member of a competitor.

Case 7, a 42-year-old health care worker at the same hospital as case 5 with no history of overseas travel, was notified to the Queensland Department of Health with PCR-confirmed measles on 8 September 2010. She had developed symptoms on 2 September 2010 and was hospitalized with pneumonitis. Further investigation showed that case 7 had been exposed to case 5 while working in the hospital ED. While infectious, case 7 attended work on two days, requiring extensive contact tracing of exposed ED patients, visitors and staff.

Case 8, a 34-year-old with no history of overseas travel, was notified to the Queensland Department of Health with serologically confirmed measles on 20 September 2010. She had developed symptoms on 17 September 2010. Further investigation showed that she had been exposed to case 7 in the hospital ED.

Case 9, a 62-year-old with no history of overseas travel, was notified to the Queensland Department of Health with serologically confirmed measles on 22 September 2010. He had developed symptoms on 17 September 2010. Further investigation showed that he had been exposed to case 7 in a general practice medical clinic.

No further cases of measles linked to this outbreak were identified.

The seven cases able to be genotyped (Table 1) had wild measles virus genotype B3 with a 100\% identical $N$ gene nucleotide sequence identified by QHFSS and VIDRL. 


\section{DISCUSSION}

This outbreak involved nine measles cases: the index case, who was infectious while on a 12-hour flight from South Africa to Australia; four passengers on the same flight; two health care workers exposed in a Queensland hospital; and two members of the public exposed in health care settings in Queensland. Five cases four infected in Australian health care settings - were hospitalized and all seven cases able to be genotyped had wild measles virus genotype B3 with identical $\mathrm{N}$ gene nucleotide sequence.

The mean incubation period for measles is 10 days (range: seven to 18 days, rarely up to 21 days). ${ }^{17}$ While incubation periods for the four first generation cases were within the range for in-flight infection, it is also possible they could have been infected in South Africa before the flight. Three of these four cases attended a common event: the BMX World Championships. During this outbreak investigation, we became aware of at least 50 other Australians attending the BMX event and that this group included members of the young adult, at-risk birth cohorts in Australia. ${ }^{18-21}$ However there were no other cases of measles in Australia linked to this event. Identical genotype and nucleotide sequence are not helpful in resolving the source of infection due to epidemic transmission of measles genotype B3 in South Africa since 2009. 22,23 Genotype B3 viruses with an identical $\mathrm{N}$ gene nucleotide sequence to that identified in this 2010 Australian outbreak (Health Protection Agency Measles Nucleotide Surveillance database reference number 12312) are known to have circulated in South Africa in 2010. ${ }^{24}$ While it cannot be definitively ascertained that in-flight transmission occurred in this outbreak, given that it could not be reliably excluded, public health action, including expanded contact tracing of other passengers on the international flight, was required.

Only one of the four first generation cases in this outbreak was seated in the initial two row contact tracing zone, with the other three seated three, four, and 16 rows behind the index case. Case 3 , seated one row from the index case, was the only first generation case identified through the two rounds of tracing of in-flight contacts. Due to the delay in diagnosis of the index case, case 2 (seated four rows from the index case) was notified with measles before contact tracing commenced. Case 6, seated three rows from the index case, was not identified in the second round of contact tracing as her details were not provided to the Queensland Department of Health.

Contact tracing of individuals seated two rows on either side of an infectious case, as recommended in Australian ${ }^{4}$ and American guidelines (personal communication: K Marienau, CDC, 22 April 2011), increasingly appears inconsistent with empiric findings from this and other recent episodes of transmission. ${ }^{8,25,26}$ The general approach in public health guidelines is to follow up all people who have shared the same air space as an infectious case for even relatively short time periods, sometimes including exposures after the case has left a room. ${ }^{13,27}$ Aircraft passengers also have multiple opportunities for exposure: for example, it seems possible that case 4 , seated 16 rows from the index case could have been exposed while queuing for the toilets (Figure 2), if not while boarding or disembarking.

Given this and other recent reports of in-flight measles transmission, $8,25,26,28$ we recommend a review of contact tracing guidelines for follow-up of in-flight measles exposures. A recent report of in-flight transmission from Australia and New Zealand, with eight secondary cases linked to two sequential flights taken by a group of three infectious co-travellers, also required an expansion of contact tracing following the identification of cases seated some distance from the index cases. ${ }^{26}$ In another instance of transmission associated with an international flight arriving in Australia, the two first generation cases were seated eight rows behind the index case. ${ }^{25}$

Flight-related contact tracing is often hampered by difficulties in obtaining comprehensive, accurate and timely passenger information from airlines and immigration departments. Airlines may be able to identify children less than two years of age in the arms of an adult, allowing contact tracing of this high risk group as recommended in European ${ }^{5}$ and American guidelines (personal communication: $\mathrm{K}$ Marienau, CDC, 22 April 2011). Targeting other passengers at higher risk of complications, such as pregnant women, the immune compromised or unvaccinated, is usually difficult due to lack of risk factor information.

Alternative contact tracing strategies that could be considered include expanding routine contact tracing beyond the two rows on either side of the case's row or considering expansion on a case-by-case basis 
depending on factors such as length of flight, cabin layout and reported (or likely) case and contact movements in flight. Routinely releasing information by press release, or providing information to everyone on the flight by e-mail or text messaging, where such contact details are available from the relevant airline, may also be worthy of consideration. Initial contact could potentially be conducted by the airline, directing passengers to information on a dedicated web page or hotline.

Any change to in-flight contact tracing guidelines should be informed by analysis of the individual and public health risks, public health resource costs involved and the potential benefits. Broader follow-up of passengers could be a more efficient and effective use of resources if the greater up-front commitment of public health resources is outweighed by the benefits of preventing community and health care setting transmission. Even small measles outbreaks can result in severe disease and generate an enormous burden in terms of public health response. Adoption of an alternative contact tracing strategy should ideally be accompanied by collection of data to evaluate effectiveness, costs and benefits.

With the increasing rarity of measles cases comes delayed diagnosis. The index case in this outbreak was not diagnosed as wild type measles until 12 days after presenting to health services in Australia, despite the suggestive laboratory findings and clinical and epidemiological circumstances, due primarily to a history of recent measles vaccination. This led to delays in notification and public health response. Case 6 was also not diagnosed as measles on her admission to hospital and was only retrospectively identified on investigation of case 5 . This missed diagnosis represents another potential point at which cases $5,7,8$, and 9 , and their associated public health workload, could have been prevented.

High levels of vaccination and herd immunity are the keys to achieving and maintaining measles elimination. ${ }^{29}$ However, given that most cases in Australia and other countries where measles elimination has been achieved are imported or linked to imported cases, a greater focus on vaccination before travel to countries with endemic or epidemic disease transmission may be of benefit. Of the seven cases in Australian residents in this 2010 outbreak, three were returned travellers aged 25 to 38 years, two were health care workers aged 32 and 42 years, and one was a 34-year-old exposed in a hospital ED.
None had a documented history of vaccination. Only case 9 would have been considered immune, and not in need of measles vaccination, by virtue of his age (62 years old). A cohort of young adults in Australia, born approximately between 1968 and 1981, are known, through empiric outbreak evidence ${ }^{18,21}$ and serosurvey findings, ${ }^{19,20}$ to be disproportionately susceptible to measles infection. Planning an intervention aimed at this broad age group is troublesome. It needs to reach individuals who use health care services less frequently thereby avoiding opportunistic vaccination, who are frequent travellers to regions with endemically circulating measles virus ${ }^{1}$ and who make up a large proportion of health care staff. Knowledge of this immunity gap led the Australian Government to fund a young adult measles vaccination campaign in 2000 , providing free vaccine for 18- to 30-year-olds, ${ }^{30}$ but based on pre and post serosurvey data, uptake was poor. ${ }^{31}$ Given the failure of this general programme, specifically targeting travellers and health care workers may be more efficient. The large number of health care workers requiring vaccination in this outbreak is likely to be representative of lower than ideal levels of immunity in health care workers more generally. Queensland Department of Health policy recommends screening of health care workers at commencement of employment for a range of vaccine preventable diseases. However, only hepatitis B vaccination is a condition of employment. Two doses of measles-mumps-rubella vaccine are recommended for workers born during or since 1966 unless there is documented evidence of two previous doses of a measles-containing vaccine or serological immunity. ${ }^{32}$ Immune status for measles and other relevant conditions is captured in a state-wide database where vaccination occurs or documentation of immunity is provided.

Measles appears to be resurgent in many parts of the world. It is likely that even in countries such as Australia, where elimination has been achieved, measles importations and subsequent community and health care outbreaks will require increasing public health resources to manage. In this context, this outbreak report provides us with a new lesson and many reminders. Current proximity-based in-flight contact tracing guidelines require review, with consideration of whether other strategies for reducing subsequent measles transmission are warranted. It is of concern that Australian health care facilities and young adult health care workers figure prominently in this and other recent measles outbreaks. ${ }^{33,34}$ Timely and adequate control of 
transmission in health care settings has the potential to dramatically reduce case numbers in a susceptible age group and the associated public health outbreak management burden. This will require greater attention to two areas which have previously proved challenging in Australia: maximizing immunity in health care workers through workplace immunization programmes and reducing the likelihood of delayed measles diagnosis which often results in suboptimal infection control - in an era when measles cases are relatively rare.

\section{Conflicts of interest}

None declared.

\section{Funding}

None.

\section{Acknowledgements}

The authors wish to thank the many people who were involved in the public health response to this outbreak in Australia, including those in the Investigation and Response Section, Communicable Disease Prevention and Control Unit, Department of Health (Victoria), the Communicable Diseases Branch, Queensland Health, the Townsville Public Health Unit (PHU), the Sunshine Coast PHU and other Queensland Health PHUs, and the National Incident Room (Australian Government Department of Health and Ageing, Canberra). We also thank laboratory staff from the Victorian Infectious Diseases Reference Laboratory, Melbourne, Victoria, and Queensland Health Forensic and Scientific Services, Brisbane, Queensland.

\section{References:}

1. Gidding $\mathrm{HF}$ et al. Sustained measles elimination in Australia and priorities for long term maintenance. Vaccine, 2007, 25:3574-3580. doi:10.1016/j.vaccine.2007.01.090 pmid: 17300858

2. Heywood AE et al. Elimination of endemic measles transmission in Australia. Bulletin of the World Health Organization, 2009, 87: 64-71. doi:10.2471/BLT.07.046375 pmid:19197406

3. Centers for Disease Control and Prevention (CDC). Epidemiological notes and reports: Interstate importation of measles following transmission in an airport-California, Washington, 1982. MMWR. Morbidity and Mortality Weekly Report, 1983, 32(16):210,215-216.

4. Revised guidelines for the follow-up of communicable diseases reported among travelers on aeroplanes. Communicable Diseases Network of Australia, 2006 (http://www.health.gov.au/internet/ main/publishing.nsf/content/cda-cdna-gl-airtravlers.htm, accessed on 13 July 2011).
5. ECDC Guidance: Risk assessment guidelines for diseases transmitted on aircraft. PART 2: Operational guidelines for assisting in the evaluation of risk for transmission by disease. European Centre for Disease Prevention and Control, 2009 (http:// www.ecdc.europa.eu/en/publications/Publications/1012_GUI_ RAGIDA_2.pdf, accessed on 13 July 2011).

6. Amornkul PN et al. Low risk of measles transmission after exposure on an international airline flight. Journal of Infectious Diseases, 2004, 189(Suppl 1):S81-85. doi:10.1086/377698 pmid:15106094

7. Dayan GH et al,; lowa Measles Response Team. The cost of containing one case of measles: the economic impact on the public health infrastructure-lowa, 2004. Pediatrics, 2005, 116:e1-4. doi:10.1542/peds.2004-2512 pmid: 15995008

8. de Barros FR et al. Measles transmission during commercial air travel in Brazil. Journal of Clinical Virology, 2006, 36:235-236. doi:10.1016/j.jcv.2006.04.001 pmid:16720101

9. Leder K, Newman D. Respiratory infections during air travel. Internal Medicine Journal, 2005, 35:50-55. doi:10.1111/ j.1445-5994.2004.00696.x pmid:15667469

10. Mangili A, Gendreau MA. Transmission of infectious diseases during commercial air travel. Lancet, 2005, 365:989-996. doi:10.1016/S0140-6736(05)71089-8 pmid:15767002

11. Fielding JE; Outbreak Investigation Team. An outbreak of measles in Adelaide. Communicable Diseases Intelligence, 2005, 29: 80-82. pmid: 15966680

12. Measles national surveillance case definition for the Australian National Notifiable Diseases Surveillance System. Communicable Diseases Network of Australia, 2004 (http://www.health.gov.au/ internet/main/publishing.nsf/Content/cda-surveil-nndss-casedefscd_measl.htm, accessed on 13 July 2011).

13. Measles: Nationalguidelines forpublic health units. Communicable Diseases Network of Australia, 2009 (http://www.health.gov. au/internet/main/publishing.nsf/Content/55AD336B864C720 3CA25755F000307B6/\$File/measles-song.pdf, accessed on 13 July 2011).

14. About Communicable Diseases Network Australia. Communicable Diseases Network of Australia, 2011 (http://www.health.gov. au/internet/main/publishing.nsf/content/cda-cdna-cdna.htm, accessed on 13 July 2011).

15. World Health Organization. Expanded Programme on Immunization (EPI). Standardization of the nomenclature for describing the genetic characteristics of wild-type measles viruses. Weekly Epidemiological Record, 1998, 73:265-269. pmid: 9745371

16. Malawi: Measles Epidemic. Bangkok, International Federation of Red Cross and Red Crescent Societies, 2010 (http:// www.ifrc.org/docs/appeals/10/MDRMW006DREF.pdf, accessed on 13 July 2011).

17. Heymann D, editor. Control of communicable diseases manual. $19^{\text {th }}$ edition ed. Washington, American Public Health Association, 2008.

18. Davidson N et al.; Outbreak investigation team. A measles outbreak among young adults in Victoria, February 2001. Communicable Diseases Intelligence, 2002, 26:273-278. pmid: 12206382

19. Gidding HF, Gilbert GL. Measles immunity in young Australian adults. Communicable Diseases Intelligence, 2001, 25: 133-136. pmid:11596715

20. Kelly HA et al. Measles immunity among young adults in Victoria. Communicable Diseases Intelligence, 2001, 25:129-132. pmid:11596714 
21. Lambert SB et al. Measles outbreak in young adults in Victoria, 1999. Medical Journal of Australia, 2000, 173:467-471. pmid:11149302

22. Centers for Disease Control and Prevention (CDC). Measles outbreaks and progress toward measles preelimination -- African region, 2009-2010. MMWR. Morbidity and Mortality Weekly Report, 2011, 60:374-378. pmid:21451448

23. Measles outbreak 2009. South African National Institute for Communicable Diseases, 2011 (http://www.nicd.ac.za/?page= measles_outbreak\&id=92, accessed on 13 July 2011).

24. Measles Nucleotide Surveillance (MeaNS). London, Health Protection Agency, 2011 (http://www.hpa-bioinformatics. org.uk/Measles/Public/Web Front/main.php, accessed on 13 July 2011).

25. Coleman KP, Markey PG. Measles transmission in immunized and partially immunized air travellers. Epidemiology and Infection, 2010, 138:1012-1015. doi:10.1017/S0950268809991129 pmid: 19878613

26. Hoskins R et al.; Centers for Disease Control and Prevention (CDC). Notes from the field: Multiple cases of measles following exposure during air travel - Australia and New Zealand, January 2011. MMWR. Morbidity and Mortality Weekly Report, 2011, 60:851. pmid:21716200

27. National measles guidelines: local \& regional services. London, Health Protection Agency, 2010 (http://www.hpa.org.uk/ web/HPAwebFile/HPAweb C/1274088429847, accessed on 13 July 2011).
28. Centers for Disease Control and Prevention (CDC). Notes from the field: Measles transmission associated with international air travel - Massachusetts and New York, July-August 2010. MMWR. Morbidity and Mortality Weekly Report, 2010, 59(33): 1073.

29. Becker NG et al. Monitoring measles elimination in Victoria. Australian and New Zealand Journal of Public Health, 2005, 29:58-63. doi:10.1111/j.1467-842X.2005.tb00750.x pmid: 15782874

30. Campbell M. Young adult measles vaccination. Communicable Diseases Intelligence, 2000, 24:241-242. pmid:11022392

31. Kelly HA et al. Residual susceptibility to measles among young adults in Victoria, Australia following a national targeted measlesmumps-rubella vaccination campaign. BMC Public Health, 2007, 7:99. doi:10.1186/1471-2458-7-99 pmid:17555601

32. Queensland Health Policy for Immunisation of Health Care Workers. Australia, Queensland Health, 2004 (http://www. health.qld.gov.au/chrisp/ic_guidelines/23563.pdf, accessed on 13 July 2011).

33. Kelly HA, Riddell MA, Andrews RM. Measles transmission in healthcare settings in Australia. Medical Journal of Australia, 2002, 176:50-51. pmid:11936282

34. Skull SA et al. Healthcare workers continue to be at risk of measles: a case for better vaccination coverage. Medical Journal of Australia, 2001, 174:662-663. pmid:11480693 